\title{
O ESTRANHO DIANTE DO ESPELHO
}

\section{Patrícia Saceanu}

A partir do conceito freudiano de inconsciente podemos abordar a noção do estranho como um dos aspectos do psiquismo que integra, no seio da unidade presumida pelo sujeito, uma alteridade. Somos divididos, estrangeiros para nós mesmos, já que "o eu não é senhor em sua própria casa". ${ }^{1}$

No texto dedicado à questão da inquietante estranheza - "O Estranho"2 ("Das Unheimliche") - Freud retoma esta subversão, própria do pensamento psicanalítico, mostrando que os principais fatores capazes de nos despertar uma sensação de estranhamento são aqueles que nos são mais intimamente familiares, "aquilo que deveria ter permanecido oculto mas veio à luz". ${ }^{3}$

A partir de um cuidadoso estudo etimológico do termo alemão Heimlich - o familiar - Freud nos apresenta o encontro dos contrários, demonstrando que Heimlich é um termo que comporta tanto o sentido de familiar quanto o de estranho - Unheimlich. Freud toma isto como uma confirmação, inscrita na própria língua, da hipótese psicanalítica que relaciona o estranho àquilo que nos é mais íntimo. Veremos que suas formulações, neste texto, são fiéis a esta constatação semântica. Em seu estudo, Freud aponta que o que lhe interessa é mostrar que entre os diferentes matizes de significados da palavra Heimlich pertencente à casa, familiar, doméstico, íntimo - há um que é idêntico ao seu oposto. Verifica que o termo Heimlich, por um lado, refere-se ao que é familiar e agradável, mas também tem como conotação possível "algo escondido, por trás das costas de alguém, sem que os outros saibam". ${ }^{4}$ Logo, é um termo que comporta sentidos distintos,

1 Freud, S. Uma dificuldade no caminho da psicanálise [1917], ESB. 3. ed. Rio de Janeiro, Ed. Imago, 1990, Vol. XVII, p.178.

2 Freud, S. O estranho [1919], ESB. 3. ed. Rio de Janeiro, Ed. Imago, 1990, Vol. XVII.

Ibid., p.301.

4 Ibid., p. 280. 
que vão desde o familiar e conhecido, passando por secreto e oculto. até inquietante, estranho.

Hanns ${ }^{5}$ retoma este estudo lingüístico apresentado por Freud, mostrando o ponto de torção onde Heimlich passa de familiar e conhecido para inquietante e estranho: aquilo que é secreto e oculto pode ser familiar e conhecido para quem participa de um segredo, por exemplo. Por outro lado, pode ser algo inquietante e estranho para os outros excluídos. Já entre as conotações do adjetivo Unheimlich, Hanns ressalta aquela que se refere a algo de insidioso, sussurrado e secreto, como a sensação de algo grandioso que se arma sorrateiramente, de modo súbito, em torno do sujeito. Há um conteúdo fantasmagórico que o torna inapreensível e inefável, dotado de uma certa irrealidade ou de um realismo fantástico. O adjetivo mantém ainda uma acepção de estranhamento indefinível e imprevisível, diferente do sentimento de pânico diante de um fenômeno avassalador, catastrófico e bem definido.

O estranho é descrito por Freud como um fenômeno experimentado pelo sujeito, que revela sobretudo um distúrbio no eu, uma desorganização momentânea. Sabemos que o eu constitui-se precariamente como uma unidade cujo caráter ilusório é notadamente pregnante. O eu é uma totalidade imaginária, sendo fragmentado em sua própria constituição. Em "O ego e o id" ${ }^{6}$ Freud concebe o eu como a instância que responde pela unidade do indivíduo, composto de identificações a traços diversos. Constituído como um "precipitado de identificações", o eu revela em sua própria estrutura uma fragmentação. É formado por identificações que podem ser até mesmo conflitantes entre si e sua desorganização é uma possibilidade sempre presente.

Podemos dizer que a experiência de estranheza aponta para a impossibilidade da completude ambicionada pelo eu, revelando sua precariedade. $\mathrm{O}$ eu pode desorganizar-se naqueles momentos em que sua posição de "pobre escravo submetido a três senhores"7, o mundo externo, o isso e o supereu, não se sustenta de modo adequado.

5 Hanns, L. A. Dicionário comentado do alemão de Freud. Rio de Janeiro, Imago, 1996, p.231.

6 Freud, S. O ego e o id [1923]. 3. ed. Rio de Janeiro, Imago, 1990, Vol. XIX.

7 Ibid. 
Dentre os inúmeros exemplos de estranhamento citados por Freud podemos destacar o fenômeno do "duplo", definido como "o efeito de defrontar-se com a própria imagem, espontânea e inesperadamente". Como exemplo, Freud narra uma experiência própria, em que descreve sua estranheza diante da sua imagem refletida no espelho de uma cabine de trem:

Estava eu sentado sozinho no meu compartimento no carro-leito, quando um solavanco do trem, mais violento do que o habitual, fez girar a porta do toalete anexo, e um senhor de idade, de roupão e boné de viagem, entrou. Presumi que ao deixar o toalete, que ficava entre os dois compartimentos, houvesse tomado a direção errada e entrado no meu compartimento por engano. Levantando-me com a intenção de fazer-lhe ver o equívoco, compreendi imediatamente, para espanto meu, que o intruso não era senão o meu próprio reflexo no espelho da porta aberta. Recordo-me ainda que antipatizei totalmente com a sua aparência.

Ao abordar este tema justamente a partir de uma experiência pessoal, cotidiana, Freud favorece uma visão do duplo como algo constitutivo, um fenômeno ao qual todos estamos sujeitos, ao menos momentaneamente.

Gostaríamos de propor aqui uma articulação entre o Unheimlich freudiano e o narcisismo a partir do aspecto de íntima familiaridade desta estranheza que surpreende o sujeito. O narcisismo pode ser considerado como condição desta familiaridade que vemos muitas vezes mostrar-se tão estranha ao eu. A constituição de uma imagem própria e seu papel fundamental na constituição do eu mas, ao mesmo tempo, a fragilidade e o estatuto de ficção deste eu, são algumas das questões com as quais nos deparamos a partir daí.

As formulações freudianas e as contribuições de Lacan acerca do estádio do espelho ${ }^{9}$ nos mostram que a imagem própria, da qual o sujeito depende para sua constituição, só pode ser percebida como uma totalidade numa exterioridade, por exemplo, na superfície do espelho. Além disso, a apropriação desta imagem exterior por um

Freud, S. O estranho, op. cit., p.309, nota 1.

Lacan, J. O estádio do espelho como formador da função do eu [1949].

In: Escritos. Rio de Janeiro, JZE, 1998. 
bebê depende de um outro que the aponte a correspondência entre ele, esse ser desamparado e ainda sem coordenação motora, e aquela imagem integrada do espelho.

Este papel indispensável do outro para a constituição do eu e o caráter de exterioridade da imagem própria são pontos fundamentais para se pensar a questão do estranho em sua articulação com o narcisismo e nos permitem observar como a própria imagem pode se tornar fonte de estranheza.

No texto sobre o narcisismo ${ }^{10}$, Freud aponta a importância do investimento através do olhar dos pais para a constituição do eu, que é precedido pelas fantasias narcísicas reparadoras que estes construíram, ao atribuírem o estatuto de "Sua majestade, o bebê" àquele ser prematuro, totalmente desamparado e dependente de seus cuidados para sobreviver. Há uma projeção das fantasias dos pais sobre a criança, que é então vista como alguém capaz de realizar tudo aquilo que teria sido impossível ou negado aos pais:

Se prestarmos atenção à atitude de pais afetuosos para com os filhos, temos de reconhecer que ela é uma revivescência e reprodução de seu próprio narcisismo, que de há muito abandonaram (...) eles se acham sob a compulsão de atribuir todas as perfeições ao filho (...) ela será mais uma vez realmente o centro e o âmago da criação - "Sua majestade o Bebê", como outrora nós mesmos nos imaginávamos.

Deste texto sobre o narcisismo podemos depreender a função primordial do outro na constituição do eu, este outro que atribui um estatuto de onipotência ao bebê desamparado, lhe dá um nome, um lugar e uma projeção no futuro. Em geral, associa-se o narcisismo ao amor de si mesmo, o que, levado a um extremo, seria um estado de desconhecimento do outro e dos limites que este impõe. Mas sabemos que o suposto enclausuramento narcísico exige na verdade um outro, cujo desejo é o que dá consistência a "Sua majestade, o bebê".

Assim, consideramos importante enfatizar que uma reflexão acerca do narcisismo é impossível sem que se leve em conta a função

10 Freud, S. Sobre o narcisismo: uma introdução [1914]. 3. ed. Rio de Janeiro, Imago, 1990, Vol. XIV.

11 Ibid., p. 108. 
da alteridade. Neste ponto, pode nos ajudar a formulação de Lacan acerca do estádio do espelho, que nos mostra justamente como é fundamental a referência ao Outro, responsável por apontar para o espelho e anunciar para o bebê: "aquela imagem, é você".

Lacan descreve o estádio do espelho como uma identificação, a transformação produzida no sujeito que assume uma imagem:

A assunção jubilatória de sua imagem especular, por esse ser ainda mergulhado na impotência motora e na dependência da amamentaçāo que é o filhote do homem nesse estágio de infans parecer-nos-á pois manifestar, numa situação exemplar, a matriz simbólica em que o eu se precipita numa forma primordial, antes de se objetivar na dialética da identificação com o outro e antes que a linguagem Ihe restitua, no universal, sua função de sujeito.

Assim, afirma que o eu se situa numa linha de ficção, irredutível, apesar das "sínteses dialéticas pelas quais tenta resolver sua discordância de sua própria realidade", , e que a forma total do corpo, pela qual o sujeito antecipa, numa miragem, sua maturação, só the é dada como gestalt numa exterioridade. Seguindo estas formulações vemos que a imagem própria é ao mesmo tempo exterior, o que nos fornece elementos para entender como esta imagem pode tornar-se fonte de estranheza.

Lacan descreve o estádio do espelho como uma precipitação, da insuficiência para a antecipação, onde está em jogo uma identidade alienante que marcará todo o desenvolvimento do sujeito. Lacan nos mostra a função da imago da forma humana na formação do eu, através da captura, por parte da criança, da sua própria imagem no espelho, ou da imagem de um adulto que lhe sirva de suporte. Para a criança pequena, em função da descoordenação motora que decorre de sua prematuração, a imagem do outro tem valor cativante, na medida em que antecipa uma imagem unitária do corpo, percebida no espelho ou na realidade do semelhante.

12 Lacan, J. O estádio do espelho como formador da função do eu, op. cit., p.97.

13 Ibid., p.98. 
Entendemos que no fenômeno do duplo, definido por Freud como o exemplo paradigmático da inquietante estranheza, objetiva-se uma experiência do "eu é um outro". Por um momento, numa irrupção pontual, o eu apresenta-se de fato como um outro, autônomo, destacado do sujeito. Então, mostra-se evidente o fato de que o eu é uma imagem, o que é estranhamente familiar. Neste instante é ultrapassado o jogo constitutivo da oscilação dentro-fora, e a imagem mostra-se só fora, embora ainda ligada ao eu: "eu, um outro".

$\mathrm{Na}$ busca de exemplos que pudessem ilustrar o obscuro tema do estranho, Freud utilizou diversos recursos, da etimologia à análise de situações cotidianas, incluindo experiências próprias. Porém, reservou à literatura um lugar de destaque, afirmando que a experiência do Unheimlich é algo tão fugidio que a ficção o demonstra melhor, produzindo-o de modo mais estável e articulado. Sobre a importância da literatura para o estudo do estranho, afirmou: "O estranho, tal como é descrito na literatura (...) merece na verdade uma exposição em separado. Acima de tudo, é um ramo muito mais fértil do que o estranho na vida real...". ${ }^{14}$ Deste modo, Freud nos mostra claramente que é possível encontrar algo do discurso psicanalítico fora do seu dispositivo, especialmente na literatura.

Talvez não seja por acaso que recorrer a este outro discurso possa ser esclarecedor neste campo em que nos centramos aqui, já que é justamente do indizível que se trata, do ponto onde parecem faltar as palavras.

Freud atribui uma grande importância à literatura em seus estudos e permeia toda a sua obra com citações de seus escritores preferidos. Porém, podemos perceber que seu uso da literatura apresenta-se de diferentes modos, exercendo funções variadas em seu texto.

Em artigo acerca das relações entre Freud e os escritores alemães, Rouanet distingue três registros em que funcionaria a literatura na obra de Freud $^{15}$ : o primeiro é o registro legitimatório, onde os escritores são convocados como aliados e precursores, como "avalistas" de verdades controvertidas, afirmadas pela psicanálise.

Freud, S. O estranho, op. cit., p.310.

15 Rouanet, S. P. Filósofos e escritores alemães. In: Perestrello, M. (org.). A formação cultural de Freud. Rio de Janeiro, Imago, 1996, p.223. 
Neste registro Freud cita Schiller, por exemplo, atribuindo a este a autoria do dualismo psicanalítico fundamental - fome e amor. Deste modo, segundo Rouanet, a literatura transforma-se em aliada da psicanálise, ajudando-a a legitimar-se, mostrando que, por mais estranhas que pareçam, as teses psicanalíticas podem ser confirmadas pelos grandes escritores.

Já no registro hermenêutico a literatura aparece como um objeto a ser interpretado. É desse modo que Freud faz uma exegese de várias obras literárias numa perspectiva psicanalítica. Rouanet cita como exemplo a clássica interpretação freudiana da Gradiva, de Wilhem Jensen, onde o delírio do jovem arqueólogo que imagina ver uma patrícia romana perambulando pelas ruínas de Pompéia é interpretado como uma fantasia resultante de reminiscências de sua infância, recalcadas.

Por último, Rouanet aponta o registro clínico: considerando a livre circulação entre a literatura e os processos inconscientes, a literatura pode tornar-se parte do material clínico com que o analista trabalha. Muitas vezes as obras literárias afloram nas narrativas dos pacientes ou aparecem nos sonhos, lapsos ou chistes, inclusive do próprio Freud.

Devemos observar ainda, sobre os modos de apropriação da literatura por Freud, que, em diversos momentos, ele inclinou-se sobre o texto literário buscando a origem do gênio, a reconstrução fantasmática do autor e a função da arte para o sujeito. Neste sentido, Gay afirma:

(...) deduzir de uma obra fáceis inferências sobre seu criador era uma tentação permanente para os críticos psicanalíticos. Suas análises dos criadores e dos públicos da arte e da literatura ameaçavam se tornar, mesmo em mãos habilidosas e delicadas, exercícios de reducionismo (...). ${ }^{16}$

Porém, em algumas passagens, Freud teve o cuidado de negar que a psicanálise pudesse lançar alguma luz sobre os mistérios da criatividade e reconheceu os problemas de se pretender fazer uma "psicanálise aplicada".

16 Gay, P. Freud: uma vida para nosso tempo. 7. ed. São Paulo, Companhia das Letras, 1995, p.297. 
Em seu discurso preparado para a cerimônia de recebimento do Prêmio Goethe, justamente onde seria reconhecido como um grande escritor, Freud parece desculpar-se, em nome da psicanálise, respondendo às críticas que poderiam advir "por termos ofendido o respeito que lhe é devido ao tentarmos aplicar a análise a ele próprio (Goethe), por termos degradado o grande homem à posição de objeto de investigação analítica." ${ }^{\prime 17}$

Assim, consideramos importante reconhecer a ambigüidade e a complexidade nas relações de Freud com a literatura e os grandes escritores. Porém, escolhemus seguir aqui apenas uma proposta, em certos momentos vislumbrada por Freud, de utilização do texto literário enquanto possibilidade de enunciação daquilo que este tem em comum com o discurso psicanalítico.

Parece ser neste sentido, observando as estreitas afinidades que pode haver entre a psicanálise e a literatura, que Freud escreve uma carta a Schnitzler, na qual deixa transparecer sua admiração e sua identificação com este escritor, a quem chega a considerar seu "duplo", como mostra a passagem a seguir:

Acho que evitei um contato com o senhor por uma espécie de medo do duplo (...) O seu determinismo, como o seu ceticismo - que as pessoas chamam de pessimismo - o seu estar possuído pelas verdades do inconsciente, pela natureza impulsiva do ser humano, o seu abalar das certezas culturais convencionais, a aderência de seus pensamentos à polaridade do amor e da morte, tudo isso me emocionava com uma secreta familiaridade (...) Assim cheguei à conclusão de que o senhor sabe por intuição - é verdade que devido a uma aguda observação de si mesmo - tudo o que descobri depois de fatigantes trabalhos com outros homens. ${ }^{18}$

É a partir desta "secreta familiaridade" que acreditamos que a literatura pode nos servir como instrumento para enriquecer, problematizar, questionar ou mesmo elucidar certos temas aos quais a psicanálise também se dedica.

17 Freud, S. O prêmio Goethe, [1930]. 3. ed. Rio de Janeiro, Imago, 1990, Vol. XXI, p.244.

18 Jones, E. A vida e a obra de Sigmund Freud. Vol. 3. Rio de Janeiro, Imago, 1989, p.430-431. 
Em seu texto sobre o estranho, Freud ressalta os contos fantásticos como recursos fundamentais para o estudo deste tema. Referências aos olhos, ao olhar e vários tipos de instrumentos óticos, como óculos, lunetas e telescópios, permeiam grande parte destes contos, explicitando a ligação entre o estranho e o campo escópico, como em "O Homem da Areia", por exemplo, texto ao qual Freud dedica uma análise detalhada em seu artigo ${ }^{19}$. Em muitos outros contos literários que despertam estranheza semelhante, encontramos o recurso a estes elementos que remetem à visão, como o espelho, principalmente, onde o estranho aparece inevitavelmente associado a uma vacilação da própria imagem.

Concordando com Freud quanto à importância da literatura para o estudo do estranho, escolhemos aqui um conto literário que narra a estranheza de um sujeito com relação à própria imagem diante do espelho - uma situação que mostra de modo privilegiado a articulação entre o estranho e o narcisismo, que discutimos acima, e que nos fornecerá elementos para discutir como são tênues os limites entre o "constitutivo" e o "mortal". Veremos que a mesma imagem da qual um sujeito depende para se constituir pode tornar-se uma ameaça à suposta integração do eu.

Um conto de Machado de Assis intitulado "O Espelho" nos parece mostrar com precisão este duplo caráter da imagem, que constitui e aprisiona, podendo levar ao aniquilamento do sujeito. Além disso, este conto aborda a importância do outro na constituição de uma identidade, ao mesmo tempo que evidencia o extremo de uma situação na qual pretende-se que uma imagem responda pela totalidade de um sujeito.

Na cena inicial deste conto, cujo subtítulo é "esboço de uma nova teoria da alma humana", alguns cavalheiros discutem metafísica à luz de velas, quando um deles - Jacobina - dispõe-se a falar acerca da alma humana, revelando sua constatação pessoal:

Em primeiro lugar, não há uma só alma, há duas... Cada criatura humana traz duas almas consigo: uma que olha de dentro para fora, outra que olha de fora para dentro (...) A alma exterior pode ser um espírito, um fluido, um homem, muitos homens, um objeto, uma operação (...) Está claro que o ofício dessa segunda

19 Cf. Freud, S. O estranho, op. cit. 
alma é transmitir a vida, como a primeira; as duas completam o homem... Quem perde uma das metades, perde naturalmente metade da existência; e casos há, não raros, em que a perda da alma exterior implica a da existência inteira" . ${ }^{20}$

Jacobina afirma ter chegado a esta conclusão a partir de um episódio pessoal, que narra em seguida: "Tinha vinte e cinco anos, era pobre, e acabava de ser nomeado alferes da guarda nacional"21. Tal fato tornou-se o centro das atenções da modesta família que, orgulhosa, desde então passou a chamá-lo apenas de "senhor alferes".

É neste contexto de entusiasmo que Jacobina aceita o convite de uma tia, que morava num sítio "escuso e solitário", para uma estada em sua casa. A tia insistiu para que ele levasse sua farda de alferes e o recebeu com todas as honras, tomando o hábito de também chamá-lo "meu alferes": "Eu pedia-lhe que me chamasse Joãozinho, como dantes, e ela abanava a cabeça, bradando que não, que era o 'senhor alferes.".22 Era assim que todos o chamavam também no sítio, reservando para o "senhor alferes" sempre o melhor lugar à mesa, sendo o primeiro a ser servido. Foi quando a tia concedeu a Jacobina a honra de pôr em seu quarto um valioso espelho:

(...) um grande espelho, obra rica e magnífica, que destoava do resto da casa cuja mobília era modesta e simples... Era um espelho que the dera a madrinha, e que esta herdara da mãe, que o comprara a uma das fidalgas vindas em $1808 \mathrm{com}$ a corte de D. João VI. Não sei o que havia nisso de verdade; era a tradição. ${ }^{23}$

Jacobina conta que todas essas coisas, "carinhos, atenção, obséquios", provocaram nele uma grande transformação, a tal ponto que "o alferes eliminou o homem (...) Aconteceu então que a alma exterior, que era dantes o sol, o ar, o campo, os olhos das moças, mudou de natureza, e passou a ser a cortesia e os rapapés da casa, tudo o que me falava do posto, nada do que me falava do homem." 24

\footnotetext{
20 Assis, M. de. O Espelho [1882] in Contos / Uma antologia. Vol. I. São Paulo: Companhia das letras, 1998, p.402.

21 Ibid., p.404

22 Idem.

23. Ibid., p.405.

24 Idem.
} 
Foi assim que Jacobina passou algumas semanas: "era exclusivamente alferes".

Porém, sua situação transformou-se quando seus familiares tiveram que partir de repente e Jacobina viu-se só. Logo começou a ter sensações estranhas, "inexplicáveis", "era como um defunto andando, um sonâmbulo, um boneco mecânico". 25

O sono lhe dava alívio. Sonhava que se fardava e todos the chamavam novamente "meu alferes". Isso lhe fazia sentir vivo, porém, quando acordava, voltava a mergulhar em sua solidão absoluta, a angústia, o silêncio e aquilo que designou uma "terrível situação moral".

Foi então que Jacobina deu-se conta de que, desde que ficara só, não olhara uma só vez para o espelho: "Não era abstenção deliberada, não tinha motivo, era um impulso inconsciente, um receio de achar-me um e dois, ao mesmo tempo (... $)^{\prime 26}$

Ao fim de oito dias de solidão, finalmente decide olhar o espelho: "Olhei e recuei. O próprio vidro parecia conjurado com o resto do universo; não me estampou a figura nítida e inteira, mas vaga, esfumada, difusa, sombra de sombra."27 Jacobina perdeu a própria imagem diante do espelho e foi assim tomado por um pavor de enlouquecer.

Porém, subitamente, por um impulso, lembrou-se de vestir sua farda de alferes e, imediatamente, recuperou no espelho sua imagem integral: "Era eu mesmo, o alferes, que achava, enfim, a alma exterior. ${ }^{128}$ Daí em diante, a cada dia, Jacobina vestia-se de alferes e sentava-se diante do espelho por algumas horas. Assim pôde atravessar mais seis dias de solidão.

Neste conto, vemos que o sujeito se conduz a reforçar sua identificação a uma imagem, o alferes, o que lhe confere identidade e reconhecimento, apaziguando sua angústia - ao menos temporariamente - já que o estranhamento é recoberto pela colagem a uma imagem unitária. Se por um lado isso the permite escapar da angustiante despersonalização, fixa-o numa identidade alienante,

\footnotetext{
Ibid, p.408.

Ibid, p. 409 .

Idem.

Ibid, p.410.
} 
restritiva por ser única. Machado de Assis, com sua fina ironia, nos permite vislumbrar o caráter fictício e frágil de uma identidade que se pretenda unívoca.

A partir deste conto e do que discutimos acima acerca do estranho e do narcisismo, gostaríamos de propor que o tema do Unheimlich pode ter também uma grande relevância na clínica psicanalítica. Na clínica, vemos que o Unheimlich pode manifestar-se como um instante de terror, como uma surpresa angustiante, diante da abertura para o vazio que o enigma aponta. Porém, acreditamos que o estranho, este momento disruptivo que faz vacilar as fixações imaginárias, também pode ser pensado como abertura para uma possibilidade de mudança subjetiva.

A partir do momento em que se torna possível "estranhar a farda de alferes", o sujeito é capaz de iniciar seu processo de despir-se desta farda, podendo até mesmo experimentar outras, e outras, e outras... No instante em que o Heimlich se apresenta como Unheimlich, afetando o sujeito ao fazê-lo vacilar, devemos apostar que é possível, para além da angústia paralisante, a emergência ou produção de novos significantes. Reconhecer que o Unheimlich pode ter um aspecto positivo é vislumbrar uma possibilidade de construção para além desta experiência, construção de novos nomes, de novos sentidos para o familiar surgido tão estranhamente para o sujeito.

\section{REFERÊNCIAS BIBLIOGRÁFICAS}

Assis, M. de. O espelho, [1882].In: Contos / Uma antologia. Vol. I. São Paulo: Companhia das letras, 1998.

Freud, S. ESB. 3. ed. Rio de Janeiro: Imago, 1990.

Sobre o narcisismo: uma introdução. [1914]. Vol. XIV.

Uma dificuldade no caminho da psicanálise. [1917]. Vol. XVII.

O estranho. [1919].Vol. XVII.

O ego e o id. [1923]. Vol. XIX.

O prêmio Goethe. [1930]. Vol. XXI. 
Gay, P. Freud: uma vida para nosso tempo. 7. ed. São Paulo: Companhia das Letras, 1995.

Hanns, L. A. Dicionário comentado do alemão de Freud. Rio de Janeiro: Imago, 1996.

Jones, E. A vida e a obra de Sigmund Freud. Vol. 3. Rio de Janeiro: Imago, 1989.

Lacan, J. O estádio do espelho como formador da função do eu. [1949]. In: Escritos. Rio de Janeiro: JZE, 1998.

Rouanet, S. P. Filósofos e escritores alemães. In: Perestrello, M. (org.). A formação cultural de Freud. Rio de Janeiro: Imago, 1996, p.223. 